\title{
Effects of Pressor Substances on Low Density Lipoprotein Peroxidation by $\mathrm{Cu}^{++}$
}

\author{
Takeshi Watanabe', Takemichi Kanazawa', Tomohiro Osanai', and Hirobumi Metoki²
}

'Second Department of Internal Medicine, Hirosaki University, School of Medicine, Aomori, Japan.

${ }^{2}$ Reimeikyo Rehabilitation Hospital, Aomori, Japan.

\begin{abstract}
To investigate whether pressor substances accelerate low density lipoprotein peroxidation by $\mathrm{Cu}^{++}$, low density lipoprotein was dialysed against physiological saline containing 0-5 $\mu$ $\mathrm{mol} / \mathrm{I} \mathrm{CuCl}{ }_{2}$ and/or $1 \mu \mathrm{mol} / \mathrm{I}$ of various pressor substances. Lipid peroxide value of low density lipoprotein changed little with the addition of norepinephrine to the saline, but the addition of norepinephrine to $1 \mu \mathrm{mol} / \mathrm{I} \mathrm{CuCl}{ }_{2}$ accelerated the peroxidation. When low density lipoprotein was dialysed against saline with norepinephrine, epinephrine, serotonin or dopamine, there were no significant differences in the lipid peroxide values of low density lipoprotein. Although the addition of serotonin into the dialyzate did not accelerate the peroxidation of low density lipoprotein due to $\mathrm{Cu}^{++}$, the addition of norepinephrine, epinephrine and dopamine accelerated the $\mathrm{Cu}^{++}$-peroxidation with a significant increase in the acceleration rate starting at the $\mathbf{3 6}$ hour point. Thus, it is speculated that various stresses stimulating the sympathetic nervous system accelerate the peroxidation of low density lipoprotein and produce peroxidized low density lipoprotein in the blood. $J$ Atheroscler Thromb, $1997 ; 4: 85-89$.
\end{abstract}

Key words : Pressor substance, LDL peroxidation, Cathecolamine

Hyperlipidemia $(1,2)$, hypertension $(3,4)$, diabetes mellitus (5), obesity (6) and others have been mentioned as risk factors in ischemic heart diseases. Recently, peroxidized low density lipoprotein (pox-LDL) has been reported $(7,8)$ as one of the important risk factors in the mechanism of atherosclerosis. Although pox-LDL is produced (9) by dialysis of $\mathrm{LDL}$ against $\mathrm{Cu}^{++}$in vitro, the mechanism of pox-LDL production in vivo is unclear. In contrast, many pressor substances are related $(10,11)$ to the elevation of blood pressure in essential hypertension, and the hypertension complicates various atherosclerotic diseases. Thus, it is very important to clarify how poxLDL in the plasma is produced and how its production is accelerated. Aronovitch et al. (12) reported that copper

Address for correspondence: Takemichi Kanazawa, Second Department of Internal Medicine, Hirosaki University, School of Medicine, 5 Zaifu-cho, Hirosaki-city, Aomori 036, Japan.

Received December 28, 1996

Accepted for publication June 18, 1997 ions caused cell damage by forming copper-catecholamine complexes, and subsequently producing radicals. It is unclear, however, whether copper-catecholamine complex accelerates peroxidation of LDL in humans. In the present study, we investigated how $\mathrm{Cu}^{+{ }_{-}}$ induced LDL peroxidation is affected by various pressor substances.

\section{Materials and Methods}

\section{Preparation of LDL}

In tubes containing ethylenediaminetetraacetic acid (EDTA, final $2.5 \mathrm{mmol} / \mathrm{I}$ ), fasting blood for plasma isolation was collected from healthy individuals. LDL (d. 1.006$1.063 \mathrm{~g} / \mathrm{ml}$ ) was isolated by sequential ultracentrifugation according to Havel's method (13). The LDL fraction was stored at $4{ }^{\circ} \mathrm{C}$ and dialysed against physiological saline $(0.9 \% \mathrm{NaCl})$ before use.

\section{Peroxidation of LDL}

Three milliliters of $\mathrm{LDL}(300 \mu \mathrm{g}$ protein $/ \mathrm{ml})$ were 
dialysed against $2000 \mathrm{ml}$ of physiological saline containing 0,1 or $5 \mu \mathrm{mol} / \mathrm{I} \mathrm{CuCl}$. Aliquots of each LDL. were collected at 0,24 and $48 \mathrm{~h}$ after the dialysis and $1 / 100 \mathrm{vol}$. of $0.1 \mathrm{~mol} / \mathrm{I}$ EDTA solution ( $\mathrm{pH} \mathrm{7.4)}$ was added to stop the peroxidation reaction at each hour point. These methods were carried out at $4^{\circ} \mathrm{C}$.

\section{Determination of lipid peroxide (LPO)}

LPO was measured with Determiner LPO Kit (Kyowa Medex Co., Ltd., Tokyo, Japan). LDL lipids were extracted according to Bligh-Dyer's method (14) and lipid constituents were separated by thin-layer chromatography (TLC). TLCs were developed with petroleum ether:diethyl ether: acetic acid $(75: 25: 1, \mathrm{v} / \mathrm{v})$ and lipids were stained by spraying an acidic iron-reagent solution (5\% acetic anhydrous : $5 \%$ sulfuric acid : $0.05 \% \quad \mathrm{FeCl}_{3} \quad(\mathrm{v} / \mathrm{v} / \mathrm{w})$ ) and heated at $110^{\circ} \mathrm{C}$ for $20 \mathrm{~min}$.

Epinephrine, norepinephrine, dopamine and serotonin were purchased from Wako Pure Chemical Industries, Ltd. (Osaka, Japan). Platelet activating factor (PAF) was purchased from Funakoshi Co., Ltd. (Tokyo, Japan). Angiotensin II and vasopressin were purchased from Sigma Chemical Company (St. Louis, USA).

To investigate the effects of pressor substances on LDL peroxidation by $\mathrm{Cu}^{++}, 1 \mu \mathrm{mol} / \mathrm{I}$ of each pressor substance was used. Because $1 \mu \mathrm{mol} / \mathrm{l}$ or higher concentration of epinephrine was used to measure platelet aggregability in clinical examination, we needed the comparisons of pressor substances with the same amount for LDL peroxidation.

\section{Statistical analysis}

Data are expressed as mean $\pm S D$. The differences between the groups were evaluated by analysis of variance (ANOVA) and post hoc comparisons of individual groups were calculated with Fisher's PLSD test. The level of statistical significance was $p<0.05$.

\section{Results}

The effects of $\mathrm{Cu}^{++}$and norepinephrine on LDL peroxidation

The LPO value of plasma LDL obtained from blood drawn into the tubes containing $2.5 \mathrm{mmol} / \mathrm{I}$ of EDTA was $0.8 \pm 0.4 \mathrm{nmol} / \mathrm{ml}$. When LDL was dialysed against physiological saline for $48 \mathrm{~h}$ to remove EDTA, the LPO value of $L D L$ increased to $17.8 \pm 10.9 \mathrm{nmol} / \mathrm{ml}$ (group $A, n=3$ ). When LDL was stored with EDTA at $4^{\circ} \mathrm{C}$ for 1 month and then dialysed against physiological saline for $48 \mathrm{~h}$ to remove EDTA, the LPO value of LDL increased to $232.7 \pm$ $2.0 \mathrm{nmol} / \mathrm{ml}$ (group $\mathrm{B}, \mathrm{n}=3$ ). These LDLs at two peroxidation levels were prepared.

By dialysis against the saline for another 48-hour period, the LPO value of LDL in group A changed from $17.8 \pm 10.9 \mathrm{nmol} / \mathrm{ml}$ to $192.3 \pm 19.3 \mathrm{nmol} / \mathrm{ml}$ by dialysis against the saline for $48 \mathrm{~h}$ in group A (Fig. 1a), and the LPO
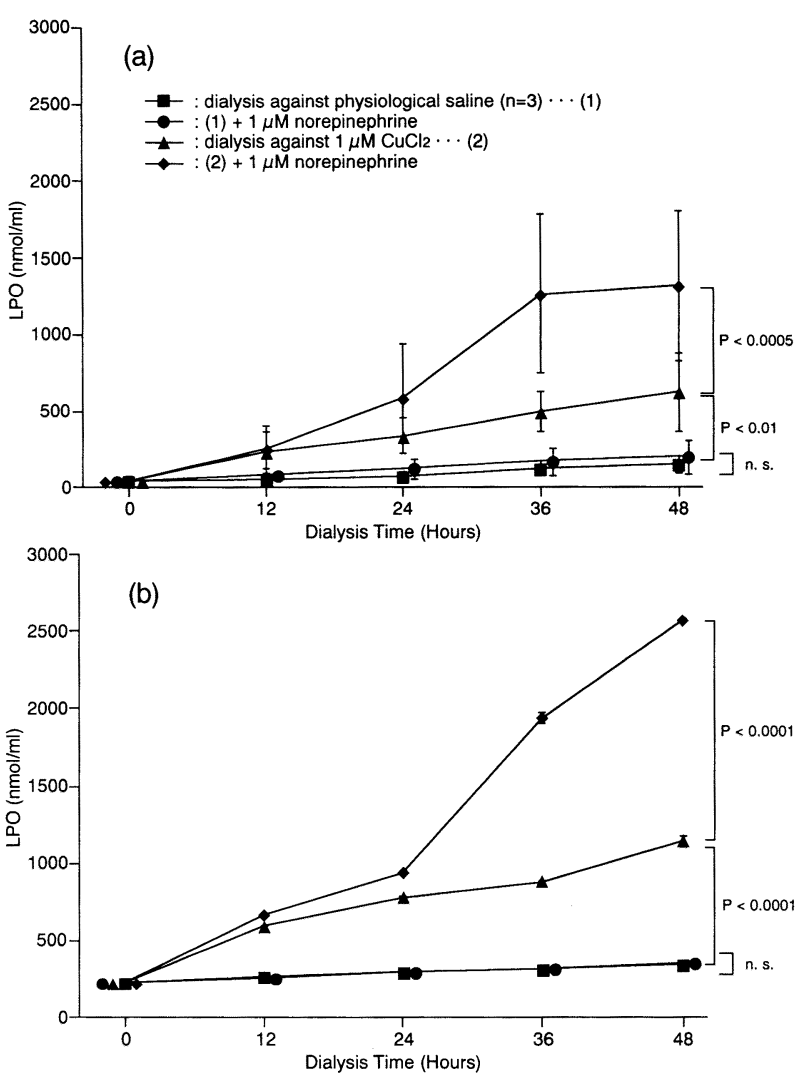

Fig. 1. Comparison of $\mathrm{Cu}^{++}$induced-peroxidation in different LDL-LPO concentration levels. (a) LDL with moderate $L P O$ values, (b) LDL with high LPO values.

value in group $B$ changed from $232.7 \pm 2.0 \mathrm{nmol} / \mathrm{ml}$ to $354.7 \pm 9.1 \mathrm{nmol} / \mathrm{ml}$ (Fig. 1b). The addition of norepinephrine to saline did not affect the peroxidation of LDL at either level.

Since LDL peroxidation by $\mathrm{Cu}^{++}$has been reported in many papers $(15,16)$, the dose response of norepinephrine to $\mathrm{LDL}$ peroxidation by $\mathrm{Cu}^{++}$was studied. As shown in Fig. 2, peroxidizability of LDL by $\mathrm{Cu}^{++}$increased with norepinephrine concentration in incubation over 24 hours.

Dialysis of LDL against $1 \mu \mathrm{mol} / \mathrm{I} \mathrm{CuCl} \mathrm{Cl}_{2}$ changed the LPO value from $17.8 \pm 10.9 \mathrm{nmol} / \mathrm{ml}$ to $446.7 \pm 37.1 \mathrm{nmol} /$ $\mathrm{ml}$ in group A (Fig. 1a) and $232.7 \pm 2.0 \mathrm{nmol} / \mathrm{ml}$ to $1144.4 \pm$ $36.0 \mathrm{nmol} / \mathrm{ml}$ in group B (Fig. 1b). The addition of norepinephrine to $1 \mu \mathrm{mol} / / \mathrm{CuCl}_{2}$ significantly accelerated the peroxidation of $\mathrm{LDL}$ : from $17.8 \pm 10.9 \mathrm{nmol} / \mathrm{ml}$ to $1014.9 \pm 287.0 \mathrm{nmol} / \mathrm{ml}$ in group A (Fig. 1a) and $232.7 \pm 2.0$ $\mathrm{nmol} / \mathrm{ml}$ to $2572.3 \pm 8.0 \mathrm{nmol} / \mathrm{ml}$ in group B (Fig. $1 \mathrm{~b}$ ).

\section{Effects of various pressor substances on LDL peroxida- tion}

Since the degree of peroxidation by $\mathrm{Cu}^{++}$did not differ between group $A$ and group $B$, subsequent experiments on the effects of pressor substances were carried out 


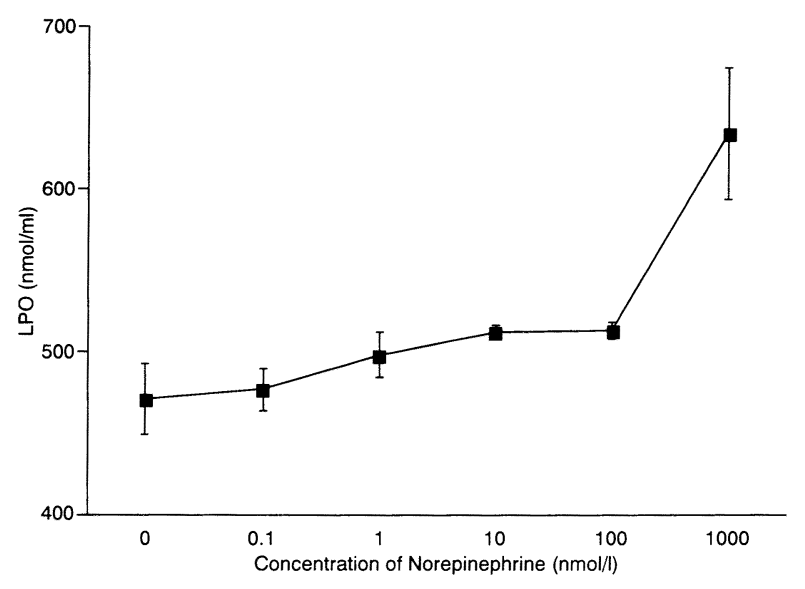

Fig. 2. Dose dependence of norepinephrine on LDL peroxidation by $\mathrm{Cu}^{++}$. LDL was dialysed against $1 \mu \mathrm{mol} / \mathrm{I} \mathrm{CuCl}_{2}$ with each concentration of norepinephrine for 24 hours. LPO value increased with concentration of norepinephrine and clear differences were found at $1,000 \mathrm{nmol} / \mathrm{l}$ norepinephrine.
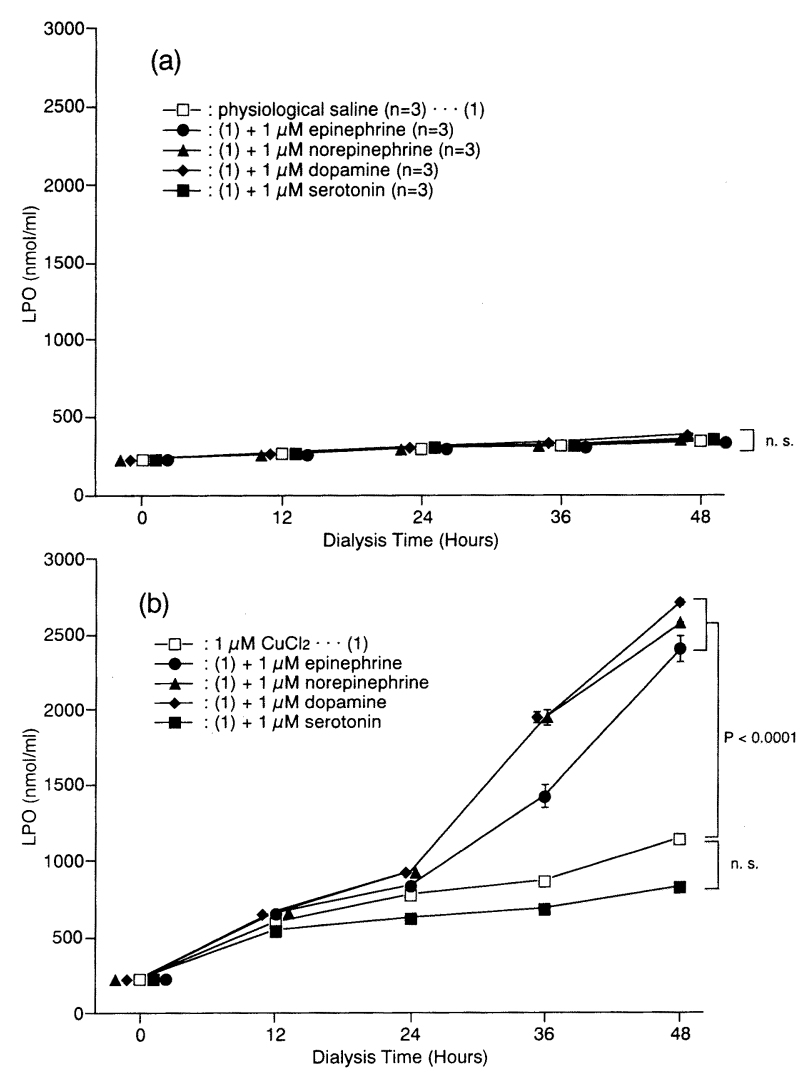

Fig. 3. Effects of pressor substances on LDL peroxidation by dialysis. LDL was dialysed against $2,000 \mathrm{ml}$ of (a) saline and (b) $1 \mu \mathrm{M} \mathrm{CuCl}_{2}$ with each pressor substance. using $L D L$ at a group $B$ peroxidation level. As shown in Fig. 3a, when LDL was dialysed against saline containing norepinephrine, epinephrine, serotonin or dopamine, no difference was noted in LDL peroxidation. As shown in Fig. 3b, however, the addition of norepinephrine, epinephrine and dopamine to $1 \mu \mathrm{mol} / / \mathrm{CuCl}_{2}$ significantly accelerated peroxidation of LDL, whereas the addition of serotonin did not. Angiotensin II, PAF and vasopressin did not affect $\mathrm{Cu}^{++}$induced-peroxidation of LDL (data not shown).

\section{Discussion}

In various aspects of life-style, i.e., exercise, stress, emotions, cold, etc., pressor substance concentrations increase or decrease in plasma or tissue. When blocking or suppressive agents are administered to patients with essential hypertension, blood pressure is reduced. Therefore, it is reasonable to assume that pressor substance concentrations are closely related to blood pressure regulation. Hypertension is an improtant risk factor in atherosclerotic diseases and, therefore, it is important to clarify whether these substances influence LDL peroxidation which is strongly related to the pathogenesis of atherosclerosis.

In our experiments, norepinephrine accelerated the peroxidation of $\mathrm{LDL}$ by $\mathrm{Cu}^{++}$independently on the peroxidized lipid level of LDL. In addition, epinephrine and dopamine also accelerated the peroxidation of LDL.

In the present experiment, $1 \mu \mathrm{mol} / \mathrm{I}$ of catecholamine was used to peroxidize LDL. This concentration of norepinephrine induced higher LPO in the incubation of $\mathrm{LDL}$ and $\mathrm{Cu}^{++}$. In addition, this concentration of cathecolamine has been used in the measurement of platelet aggregability (17). From this evidence, $1 \mu \mathrm{mol} / \mathrm{l}$ of pressor substances were used for LDL peroxidation.

According to Rump et al. (18), catecholamine produces oxygen free radicals in isolated rabbit hearts. Wysocki et al. (20) reported that hydrogen peroxide was detected in the plasma of patients with coronary heart disease who were undergoing exercise testing. Aronovitch et al. (12) published results indicating that copper ions formed complexes with epinephrine or norepinephrine, and that these complexes enhanced cell damage. The cell damage was proportional to the rate of catecholamine oxidation. Furthermore, Baraboi (19) developed a radiationstress model showing the production of lipid peroxide and the transfer of catecholamine to quinoid. He found that the quinoid intermediated radical reaction. Rosei et al. (21) reported that dopamine showed the same catecholamine reaction to oxidation.

The accumulated evidences from these reports support our findings indicating that epinephrine, norepinephrine and dopamine enhance peroxidation of $\mathrm{LDL}$ due to $\mathrm{Cu}^{++}$. Although they did not explain clearly the reason for the acceleration of radical oxidation by catecholamines, 
Aronovitch et al. (12) indicated that the formation of copper-catecholamine complexes was important in radical oxidation.

Generally, the average concentration of pressor substances in serum are $0.5-2 \mathrm{nmol} / \mathrm{l}$. However, it is known that these substances increase more and more under various pathological conditions. Therefore, pressor substances play an important role in the accelerations of LDL peroxidation.

The incubation of various cells and normal LDL induced peroxidized LDL in culture medium with $\mathrm{Cu}^{++}$. Accordingly, our results mentioned above might suggest the enhancement of LDL peroxidation in the vessels.

According to Aronovitch et al. (12), the complexes of $\mathrm{Cu}^{++}$and catecholamine enhance cell damage. Therefore, both peroxidized LDL and the damaged cells with catecholamine- $\mathrm{Cu}^{++}$complexes might influence the pathogenesis of the arterial vessels.

In our experiment, serotonin did not cause acceleration of LDL copper oxidation; rather it reduced LPO levels. It is unclear how serotonin reduces LPO levels in $\mathrm{Cu}^{++}$ peroxidation.

Sahu et al. (22) and Yoneda et al. (23) reported that flavonoids or catechin showed strong suppression of radical production. Both these chemical substances have polyphenolic structures in their molecules. According to these reports, polyphenolic structure suppresses the radical oxidation. Serotonin does not have a polyphenolic structure in its molecules. Substances such as angiotensin II, platelet activating substance or vasopressin also had no phenolic or polyphenolic structure. Accordingly, LDL peroxidation by copper ion is not accelerated.

Generally, it has been reported $(24,25)$ that polyphenol structure suppresses peroxidation. However, catecholamines which have polyphenolic structures accelerated $\mathrm{Cu}^{++}$-peroxidation. Although the reason is unclear, the specificity of the catechol structure making $\mathrm{Cu}^{++}$ complex might be considered as one reason for the acceleration of $\mathrm{Cu}^{++}$-peroxidation. Further experiments are necessary to determine the explanation.

\section{References}

(1) Nielson LB: Transfer of low density lipoprotein into the arterial wall and risk of atherosclerosis. Atherosclerosis, 123: 1-15, 1996

(2) Stary HC, Chandler AB, Glagov S, Gyton JR, Insull W Jr, Rosenfeld ME, Schaffer SA, Schwartz CJ, Wagner WD, and Wissler RW: A definition of initial, fatty streak, and intermediate lesion of atherosclerosis. A report from the Committee on Vascular Lesions of the Council on Arteriosclerosis. Circulation, 89 : 2462-2478, 1994

(3) Roman MJ, Pickering TG, Pini R, Schwarz JE, and Devereux RB: Prevalence and determinants of cardiac and vascular hypertrophy in hypertension. Hypertension, 26 : 369-373, 1995
(4) Swartz SM and Ross R: Cellular proliferation in atherosclerosis and hypertension. Progr Cardiovasc Dis, 26 : 355-372, 1984

(5) Bowie $A B$, Owens $D$, Cullis $P$, Johnson $A$, and Tomkin $\mathrm{GH}$ : Glycosylated low density lipoprotein is more sensitive to oxidation: implications for the diabetic patient? Atherosclerosis, 102: 63-67, 1993

(6) Kreger BE : Coronary Risk Factors: Insights from Framingham. Clin Cardiol, 14 : III-3-III-12, 1991

(7) Kanazawa T, Osanai T, Uemura T, Onodera K, and Oike $Y$ : Evaluation of oxidized low-density lipoprotein and large molecular size low-density lipoproteins in atherosclerosis. Pathobiology, 61: 200-210, 1993

(8) Steinberg D: Role of oxidized LDL and antioxidants in atherosclerosis. Adv Exp Med Biol, 369: 39-48, 1995

(9) Kanazawa T, Kaneko H, Uemura T, Konta Y, Onodera K, Metoki $\mathrm{H}$, and Oike $\mathrm{Y}$ : Acceleration of platelet aggregability due to moduration of native LDL. Circ Res, 66: 1166-1169, 1990

(10) Page IH: Hemodynamics. In: Hypertension mechanism. ed by Page $\mathrm{IH}$, pp 6-92, Grune \& Stratton Inc, Orlando, 1990

(11) Saruta $T$ : Mechanism of glycocorticoid-induced hypertension. Hypert Res Clin Exp, 19: 1-8, 1996

(12) Aronovitch J, Godinger G, and Czapski G: Bactericidal activity of catecholamine copper complexes. Free Radic Res Commun, 12-13 (Pt 2) : 479-488, 1991

(13) Havel RJ, Eder HA, and Bragdon JH: The distribution and chemical composition of ultracentrifugally separated lipoproteins in human serum. J Clin Invest, 51: 14861494, 1955

(14) Bligh EG and Dyer WJ : A rapid method of total lipid extraction and purification. Can J Biochem Physiol, 37 : 911-917, 1959

(15) Hessler JR, Morel DW, Lewis LJ, and Chisolm GM: Lipoprotein oxidation and lipoprotein-induced cytotoxity. Arteriosclerosis, 3 : 215-222, 1983

(16) Quehenberger O, Koller E, Jurgens G, and Esterbauer H : Investigation of lipid peroxidation in human low density lipoprotein. Free Radic Res Commun, 3 : 233-242, 1987

(17) Lentini S, Bulong $E$, and Pirro $C$ : Arterial hypertension and platelet aggregation in the pathogenesis of cerebrovascular diseases. In: Platelet aggregation in the pathogenesis of cerebrovascular diseases. ed by Agnoli $A$ and Fazio C, pp 152-166, Springer-Verlag, Berlin Heidelberg New York, 1974

(18) Rump AF and Klaus W: Evidence for norepinephrine cardiotoxicity mediated by superoxide anion radicals in isolated rabbit hearts. Naunyn Schmiedebergs Arch Pharmacol, 349 : 295-300, 1994

(19) Baraboi VA : Ro'l perekisnogo okisleniia v mekhanizme stressa. Fiziol Zh, 35: 85-97, 1989

(20) Wysocki H, Ka'zmierczak $M$, and Wykr Cetowicz A: Peroxide plasma level in patients with coronary heart disease as a possible indicator of ischemia during exercise test. Coron Artery Dis, $4: 645-647,1993$

(21) Rosei MA, Blarzino C, Foppoli C, Mosca L, and Coccia $\mathrm{R}$ : Lipoxygenase-catalyzed oxidation of catecholamines. Biochem Biophys Res Commun, 200: 344-350, 1994

(22) Sahu SC and Gray GC : Interactions of flavonoids, trace metals, and oxygen: nuclear DNA damage and lipid peroxidation induced by myricetin. Cancer Lett, 70: 
73-79, 1993

(23) Yoneda $T$, Hiramatsu $M$, Sakamoto $M$, Togasaki $K$, Komatsu $\mathrm{M}$, and Yamaguchi $\mathrm{K}$ : Antioxidant effects of "bCATECHIN". Biochem Mol Biol Int, 35: 995-1008, 1995

(24) Salah N, Miller NJ, Paganga G, Tijburg L, Bolwell GP, and Rice-evans C : Polyphenolic flavonols as scavengers of aqueous phase radicals and as chain-breaking antioxidants. Arch Biochem Biophys, 322: 339-346, 1995

(25) Lee SF, Liang YC, and Lin JK: Inhibition of 1,2,4-benzenetriol-generated active oxygen species and induction of phase II enzymes by green tea polyphenols. Chem Biol Interact, 98: 283-301, 1995 